\title{
Research Paper: A Study of the Processes and Contextual Factors of Marital Infidelity
}

\author{
Neda Atapour ${ }^{1^{*}}$ (i), Mohammad Reza Falsafinejad ${ }^{2 *}$ if, Khodabakhsh Ahmadi ${ }^{3}$, Anahita Khodabakhshi-Koolaee ${ }^{4 *}$ (i) \\ 1. Department of Counseling, Faculty of Humanities and Social Sciences, Science and Research Branch, Islamic Azad University, Tehran, Iran \\ 2. Department of Measurement, Faculty of Psychology and Educational Sciences, Allameh Tabatabai University, Tehran, Iran. \\ 3. Behavioral Sciences Research Center, Baqiyatallah University of Medical Sciences, Tehran, Iran. \\ 4. Department of Psychology and Educational Sciences, Faculty of Humanities, Khatam University, Tehran, Iran.
}

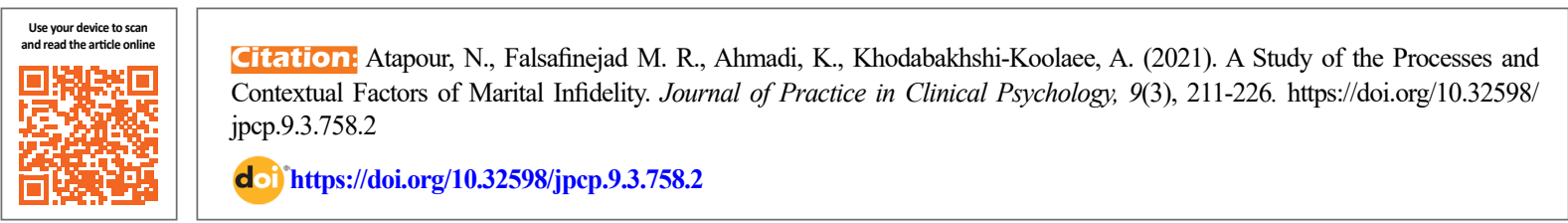

\section{(c) (1) (8)}

Article info:

Received: 24 Mar 2021

Accepted: 11 May 2021

Available Online: 01 Jul 2021

\section{Keywords:}

Family Conflict, couples , Grounded theory

\section{ABSTRACT}

Objective: An increase in post-marital relationships has had adverse consequences. One of the consequences is family dissolution and the breakdown of social units (families). The present study aimed to study the processes and contextual factors of marital infidelity.

Methods: This qualitative study was conducted using the grounded theory method. The research population included couples who experienced marital infidelity. A total of 32 participants were selected using the purposive sampling method in 2019. We conducted semi-structured interviews with the participants to collect the study data, and the interviews continued until the data saturation. The collected data were systematically analyzed in three stages of open, axial, and selective coding.

Results: Analysis of the data collected revealed 51 codes extracted through open coding Then, the extracted codes were merged into 10 categories via axial coding. These categories included four themes: the formation of the context of marital infidelity, predictions of marital infidelity, engaging in marital infidelity, and the consequences of marital infidelity.

Conclusion: Given that marital infidelity is a complex and multifaceted phenomenon, the insights from this study can be used to develop models to identify and prevent predictors of marital infidelity.

"Corresponding Author:

Mohammad Reza Falsafinejad, PhD.

Address: Department of Measurement, Faculty of Psychology and Educational Sciences, Allameh Tabatabai University, Tehran, Iran.

Tel: +98 (21) 48390000

E-mail:falsafinejad@atu.ac.ir 


\section{Highlights}

- Couples have starting marital relationships with many wishes.

- However, some marriages inevitably run into problems that end in divorce and separation.

- One of these problems is infidelity, which is the most critical threat to the functioning, stability, and continuity of marital relationships.

- The results of present research showed that, predictors of marital infidelity were including; marital conflict/violent behavior, Emotional and sexual apathy.

- In addition, consequences of marital infidelity were emotional divorce, Separation/divorce, and trying to get back to normal life.

\section{Plain Language Summary}

Infidelity is a one of reason to critical threat to the functioning, stability, and continuity of marital relationships. Present study indicated that the couples were chose one of these options such as; emotional divorce, Separation/divorce, and trying to get back to normal life.

\section{Introduction}

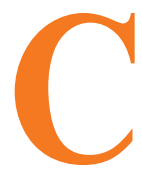

ommitment in marital relationships is one of the most critical issues for couples in the current period. Couples engage in marital relationships and form a family with many hopes and usually tend to be optimistic about the success of their marriage (Koolaee, Motlagh, Esmaili, \& Rahmatizadeh, 2014). Couples also tend to see marital life as a channel for growth, prosperity, excellence, happiness, and peace for themselves and their children (Olson, DeFrain, \& Skogrand, 2010). However, some marriages inevitably run into problems that end in divorce and separation. One of these problems is infidelity, which is the most critical threat to the functioning, stability, and continuity of marital relationships (Mark, Janssen, \& Milhausen, 2011). Infidelity reduces couples' trust and finally leads to absolute mistrust (Farooq, \& Fatima, 2018). Findings from field studies also indicated that one of the main causes of divorce is marital infidelity, which refers to mistrust in marital relationships (Baucom, Pentel, Gordon, \& Snyder, 2017). Infidelity is a behavioral disorder that leads to abnormal and undesirable consequences and creates many problems for both the betraying and betrayed spouses. It may also lead to shock, disbelief, denial, beatings, murder, suicide (Fincham \& May, 2017), marital crisis, dysfunctions in parenting roles, job problems (Gordon, Baucom, \& Snyder, 2005), family breakdown, and the separation of couples (Jahan et al., 2017).
Marital infidelity is the crossing of marital boundaries and the establishment of physical or emotional intimacy outside the marriage relationship (Özgun, 2010; Munsch, 2018) with the hope of satisfying one's psychological needs (Apostolou, 2019). Marital infidelity, especially in Eastern societies, causes a profound shock to the partner and family (Farooq, \& Fatima, 2018). In modern societies, despite changes in boundaries of the emotional relationship, commitment and monogamy are still considered commonly accepted principles (Olson et al., 2010). Although marital infidelity is an unacceptable practice and a major fault in relationships, it is still a widespread phenomenon (Fife, Weeks, \& Stellberg, 2013). Tsapelas, Fisher and Aron (2010) reported that $85 \%$ to $90 \%$ of the participants agreed with monogamy and the monopoly of sexual and emotional relations with the spouse. However, 70\% were always worried about their partner's infidelity, and many had experienced marital infidelity at least once.

Another study in the United States found that $21 \%$ of men and $11 \%$ of women commit infidelity during their lifetime (Snyder, Baucom, \& Gordon, 2007). Other studies have reported marital infidelity to be $44 \%$ in men and $25 \%$ in women (Wright, 1994). Stephanlo and Olla (2012; cited in Jones \& Weiser, 2014) and Ein-Dor, Perry-Paldi, Hirschberger, Birnbaum, and Deutsch (2015), in a study conducted in the United States, reported that $21 \%$ to $25 \%$ of men and $11 \%$ to $15 \%$ of women had committed marital infidelity at least once in their life- 
time. However, Aivess and Esmith (2007; cited by Tsapelas et al., 2010), in a similar study conducted in the United States, concluded that the prevalence of marital infidelity among American women is $26 \%$ to $70 \%$ and among American men is 33\% to 75\%. Mark et al. (2011) found that one-third of men and one-quarter of women have experienced marital infidelity at least once in their lifetime. According to statistics released in the United States in 2014, 41\% of American couples (either both couples or one of them) have committed physical or emotional infidelity.

Although no specific study has addressed the prevalence and percentage of marital infidelity in Iran, many studies have reported cases of this crisis among couples (Koolaee et al., 2014). According to a study conducted in 15 provinces of Iran, marital infidelity was the cause of $67 \%$ of murders of men by their wives. Moreover, the most important causes of divorce in Iran in 2012 were marital infidelity, economic issues, and the addiction of couples. Also, ideological issues and family interventions were the main reasons for divorce in 2013, followed by marital infidelity and sexual dissatisfaction as the leading causes of divorce in 2014 (KhodabakhshiKoolaee, A., Bahrami, \& Rasstak, 2017).

Marital infidelity refers to any hidden sexual or emotional relationship that, if disclosed, can disrupt a couple's relationship. Accordingly, marital infidelity is recognized as a growing crisis in Iran, which is associated with serious harm to the individual, marital, family, and social relationships and plays a major role in family dissolution and divorce (Khodabakhshi-Koolaee et al., 2014). Consequently, marital infidelity is associated with catastrophic communication problems such as emotional death, emotional apathy, spousal mistrust, dysfunctions in parenting roles, job problems, communication dissatisfaction, communication maladjustment, less communication intimacy, and finally, divorce (Tsapelas et al., 2015; Eindor et al., 2015; Jenkins, 2015).

Marital infidelity also leads to mental disorders (posttraumatic stress disorder, depression, anxiety, obsession, and nightmares) and physical disorders (gastrointestinal, cardiovascular, and respiratory problems) (Fincham \& May, 2017). In addition, couples who undergo treatment for marital infidelity are more likely to separate and get a divorce than couples who refer for therapy for other problems (Hawkins, Willoughby, \& Doherty, 2012). As a result, prevention of this socially harmful phenomenon improves the performance of couples involved in this phenomenon and reduces its adverse consequences on the family, child-rearing, and mental health of society.
Moreover, it helps reduce the costs of mental and physical therapies associated with infidelity and decreases divorce rates. This issue underscores the importance of identifying the processes and contextual conditions of marital infidelity.

Brown (2013) argued that marital infidelity results from the interaction of several factors and processes that start from premarital life in the context of the paternal family and continue to affect spouse selection and problems during marital life conducted a study entitled "Family background and propensity to engage in infidelity" (Khodabakhshi-Koolaee et al., 2017). They concluded that there are associations between infidelity, family-oforigin experiences, parental infidelity, family conflicts, and individuals' infidelity beliefs. Marital infidelity is a multifaceted issue whose underlying factors cover different intrapersonal, interpersonal, and environmental aspects (Khodabakhshi-Koolaee et al., 2017). However, the reasons behind the formation of this problem are still not entirely known (Foster \& Misra, 2013; Shackelford, Besser, \& Goetz, 2008).

Thus, given the increase in marital infidelity in the community, its psychological and social consequences, its impact on marital relations, and the structure of families, an analysis of contextual and underlying factors of this phenomenon seems essential. Besides, previous studies have revealed the necessity of identifying the factors influencing marital infidelity and the processes associated with this phenomenon in designing and implementing preventive and treatment programs to reduce this crisis and its destructive effects. Since the issue of marital infidelity is one of the most private individual-family issues, the exploration of its underlying factors is possible only through face-to-face conversation and interviews.

Accordingly, the present study aims to examine contextual factors and processes of marital infidelity using a qualitative approach and based on the grounded theory by exploring the lived experiences of people who have been involved in this phenomenon. In addition, conducting scientific surveys to identify the factors associated with this problem and its consequences in society is essential. Different studies have been conducted in other countries to explore the causes and factors underlying marital infidelity and identify effective treatment and prevention techniques. However, due to the high sensitivity of marital infidelity, difficulty in accessing individuals who experienced or were involved in this issue, and negative communal and regulatory reaction to people who commit it, there is little research on this issue in Iran. Also, experts and researchers have not seriously 
paid attention to marital infidelity as a threat to the safety and health of individuals, families, and society. Thus, exploring the roots of this problem and planning to prevent, reduce, and eliminate its underlying factors can effectively maintain and improve social health, order, and balance. Accordingly, this study aims to identify the processes and contextual conditions of marital infidelity.

\section{Materials and Methods}

The present study used a qualitative and grounded theory approach to develop a scientific perspective through a systematic approach and direct use of data instead of making an inference based on previous assumptions and existing theoretical frameworks. A grounded theory approach requires using several stages of data collection, refinement, and review of relationships between informational categories. In qualitative studies, especially in the grounded theory approach, data are collected using exploratory interviews. Besides, data collection and analysis are performed simultaneously to extract the theory grounded in the data (Creswell \& Báez, 2020).

Accordingly, to identify the processes and contextual factors of marital infidelity in this study, the narratives of couples who have experienced marital infidelity were examined by interviewing the couples. The participants were selected from those referred to courts of law and marriage and family therapy clinics, both private and public, in Tehran in late September 2019. To this end, the questions to be asked in semi-structured interviews were prepared by reviewing previous studies in the literature. Afterward, to examine the content and adequacy of the questions, they were reviewed by several marriage and family therapists and researchers. After preparing the final questions, the interviews were conducted with couples who had the experience of marital infidelity.

The participants were selected using the purposive sampling method. The inclusion criteria for the couples were having experienced marital infidelity at least once in their marital life, being married for 1 to 10 years, having no acute mental illness at the discretion of a psychiatrist, and providing informed consent to participate in the study. To this end, persons who met the inclusion criteria and volunteered to participate in this study were selected. The selection of participants continued until the data collected through the interviews were theoretically saturated, i.e., no new information was observed with additional interviews with new participants. Accordingly, the data were saturated by interviewing 32 persons. The exclusion criteria were being in divorcing process, being in love or sexual relationship with a third party, consuming alcohol and or drugs that may lead to high-risk behaviors such as infidelity.

Collecting data from the interviews and observations continued until the collected data were saturated and no new information was obtained with additional interviews. One of the signs of data saturation is to find out repetitive data in interviews and observations. Each interview lasted between 45 minutes and an hour. Before starting the interviews, some necessary information was provided to the participants about the research procedure and confidentiality of the participants' data as a requirement for compliance with ethical principles. Besides, written informed consent was obtained from the participants. At the time of the interviews, the participants' voices were recorded with their permission. Then, the recorded interviews were transcribed carefully word by word. In parallel with the interview process, the data were analyzed, and interviews with new participants were conducted until the data were saturated. The transcripts of the interviews were then analyzed.

A systematic method was used to analyze the content of the interviews and extract the related themes and categories. A systematic research design based on the grounded theory emphasizes the use of data analysis through open coding (to extract basic constructs), axial coding (to reveal codes, categories, and subcategories), and selective coding (to extract the core category). To this end, we performed open coding based on the research variables, the questions asked in the interviews, and the participants' statements. Then, axial coding was used to refine and separate the identified categories (the statements with similar meanings). Finally, selective coding was done to merge the categories into a coherent pattern. The criteria proposed by Guba and Lincoln (1994) were used to ensure the trustworthiness of the data. Thus, to increase the data validity, the data collection and analysis were performed simultaneously until the collected data were theoretically saturated.

The credibility of the data was checked by having the transcripts reviewed by the participants. This review helped the researcher better understand their experiences and increased the participants' trust. The data confirmability was ensured by reviewing the transcripts and reaching a consensus on the extracted codes and categories through member checks. Also, the dependability of the data was established through external checks and reviews of the collected data. Finally, the transferability of the findings was enhanced by interviewing additional persons and refining the data. Written informed consent was obtained from the participants for conducting and 
recording the interviews, voluntary participation in, and withdrawal from the study. Also, the participants' information was kept confidential.

\section{Results}

The results showed that out of 32 people who experienced marital infidelity, 21 were females, and 11 were males. The female participants' mean age was 38.75 years with a range of 26 to 56 years. Besides, the male participants' mean age was 42.67 years with a range of 29 to 61 years. The mean age of all couples was 39.71 years. Furthermore, 15 participants had a diploma, 10 had a bachelor's degree, and 7 had high school and lower education. The participants married for 4 to 30 years with a mean of 18.9 years. Moreover, the participants' length of marriage ranged from 16 to 30 years, and their average marriage length was 21 years. All participants had children, with 19 persons having one child, 9 having two children, and 4 having three children. A total of 21 participants (including 11 men and 9 women) were employed, and the rest were unemployed or homemakers.

All participants' spouses were employed. The majority of the participants had moderate socioeconomic status, 8 persons poor socioeconomic status, and 4 good socioeconomic status. The majority of the participants (18 persons) reported that they knew their spouse through family or friends; 7 participants met their spouse at work, 4 at university, and 3 at a party. Besides, most participants (24 persons) reported that they were married out of love, and 8 people stated that they were married because of the family members' insistence. Half of the participants stated that they were boyfriends or girlfriends before marriage, but half reported no premarital relationships. The participants also said that they spend an average of 4.5 hours per day on social media. Most participants reported that they watched movies and TV shows on satellite channels infrequently, but all watched porn movies.

The majority of participants ( 23 persons) reported that they experienced marital infidelity for more than 5 years after marriage; 7 reported that they experienced marital infidelity for 2 to 5 years after marriage, and 2 people also reported that they had this experience less than two years after their marriage. Besides, 14 participants reported that they already knew a third person who had entered into a marital relationship with their spouse and 12 people reported that they met the third party at work or school and 6 people reported meeting the third person through online social media. The majority of participants ( 15 persons) reported that their partner's or their infidelity was exposed by checking cell phones and online chat rooms.
Also, 10 persons stated that they learned about their partners' cheating through their friends' and relatives' reports, and 7 people reported that they discovered partners' cheating accidentally when going to work or home.

Finally, most participants (21 persons) reported that their spouse was unfaithful, and 11 persons reported themselves committing marital infidelity.

The analysis of the participants' experiences revealed 51 codes (themes) that were extracted through open coding. The extracted codes were merged into 10 categories via axial coding. Finally, 10 main themes were identified through selective coding, as shown in Table 1.

As seen in the above Table, the process and contextual conditions of marital infidelity are divided into four main themes: the formation of the context for marital infidelity, predictions of marital infidelity, engaging in marital infidelity, and consequences of marital fidelity.

This section provides examples of the participants' statements about the main categories at the four levels of marital infidelity process inputs, marital infidelity process formation, marital infidelity process, marital infidelity process outputs, and their related subcategories. Aliases were used in the participants' statements.

\section{The formation of the context for marital infidelity}

\section{The formation of the context for marital infidelity in the premarital life}

The tense and disturbing environment of the paternal home, the cold relations of family members, strictness and control of comings and goings, etc., have caused some participants who had experienced marital infidelity, especially the women to surrender to marriage without interest and knowledge, to get rid of these problems and gain freedom. Also, some male participants acknowledged that their parental house was tense and without intimacy between family members.

\section{Maryam said:}

"We had cold relationships in the family. My parents did not have good relations. My comings and goings were controlled by my parents and brothers. I was not allowed to answer the phone. My mother was always getting on my nerve and beat me. I wished I could marry sooner and leave home" (Escape from home).

Some participants engaged in extramarital affairs said that their parents had already cheated on their spouses 
Table 1. The codes extracted via open, axial, and selective coding

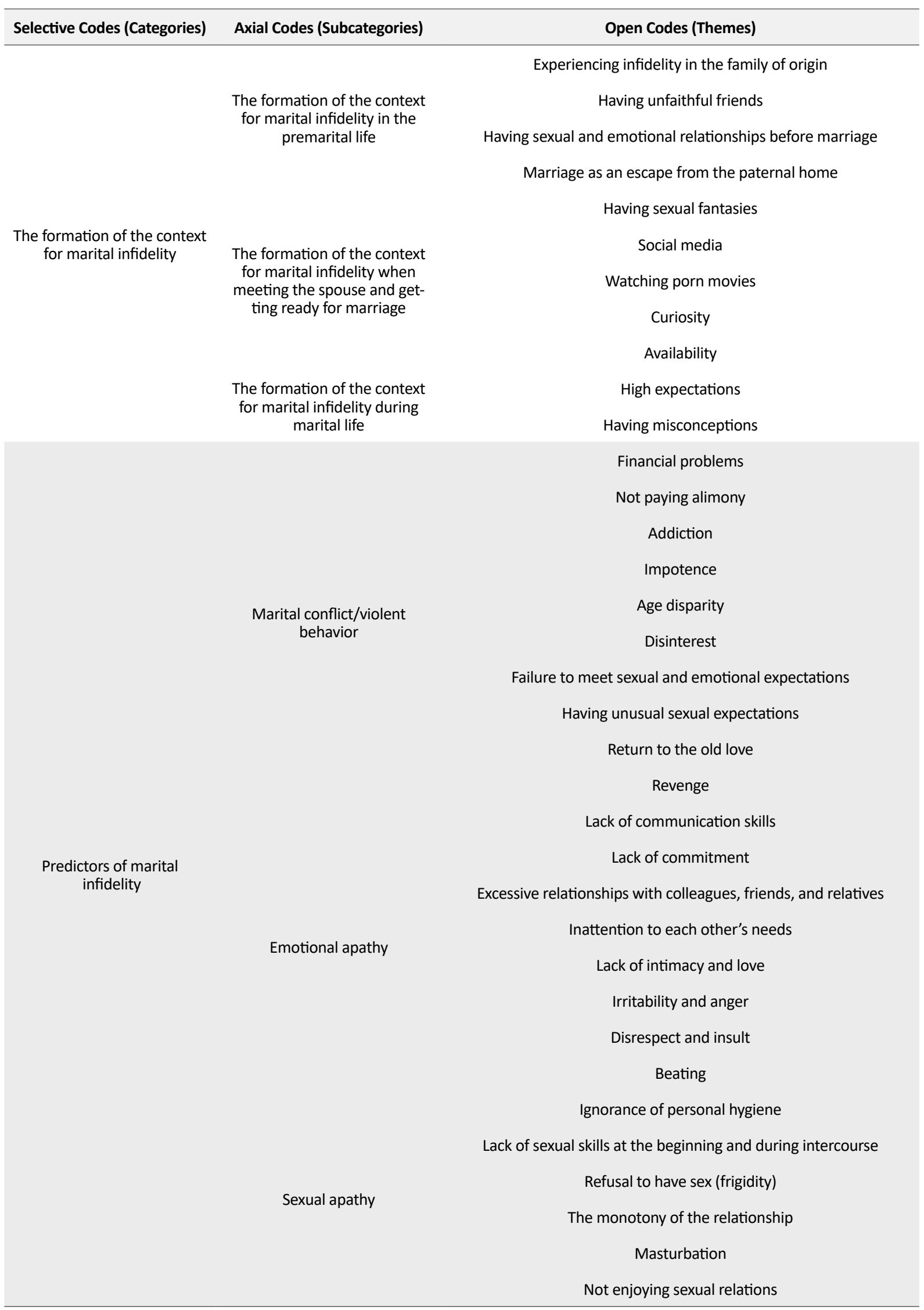




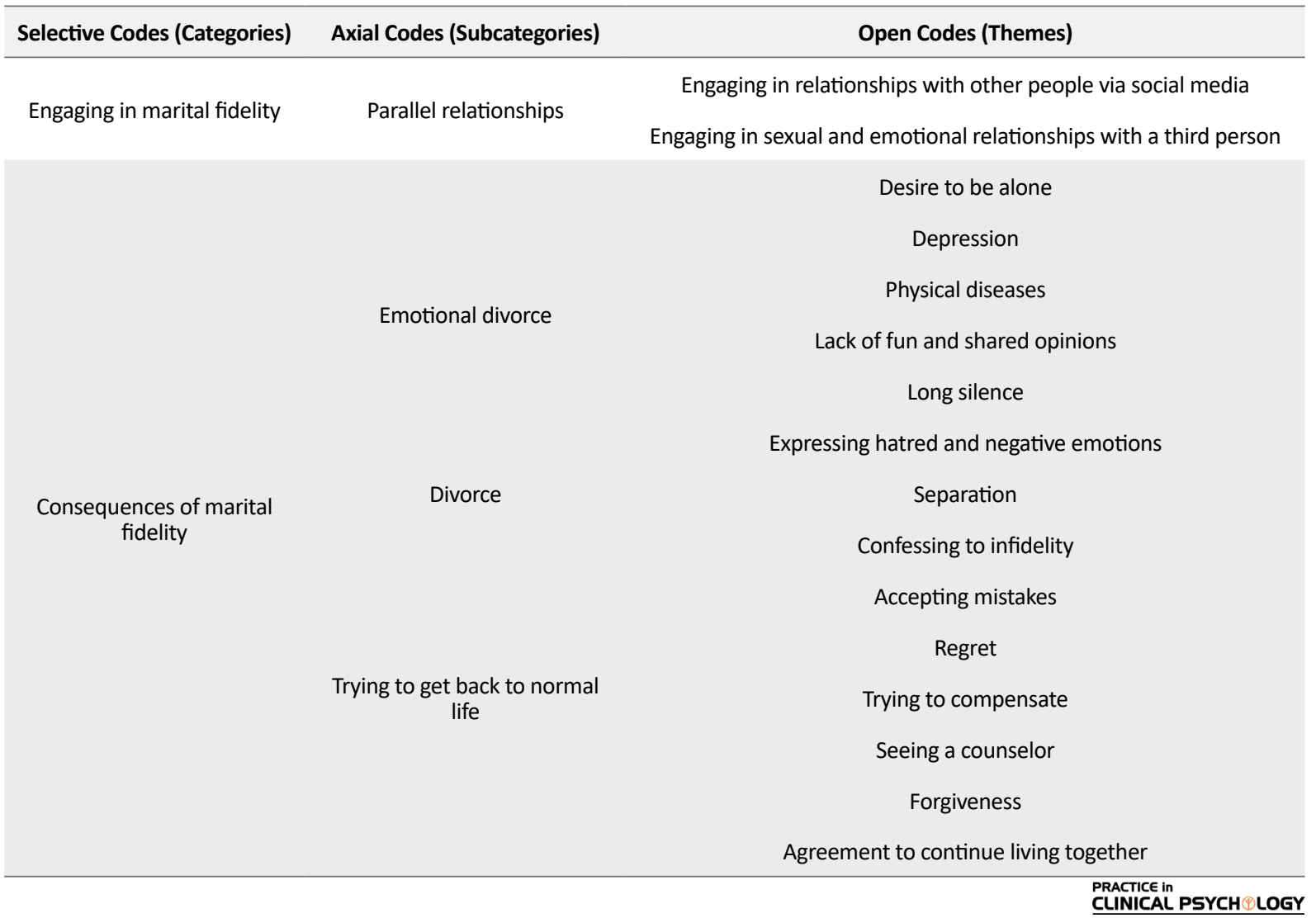

and witnessed these events and their consequences in the family. This means that unfaithful parents affirm infidelity and justify it to their children.

\section{Solmaz said:}

"I remember when I was about 14 years old, one day my mother and I went shopping, and my mother became friends with the shopkeeper, and after that, they called each other. I was very upset about this, but later I realized that my mother was right because my father bothered her a lot."

Most unfaithful men and about half of the women surveyed stated that they had an affair with the opposite sex before marriage, and some even had sex. This relationship was also repeated by some participants after marriage, and since their marriage, they had the idea of having a relationship with the opposite sex. Therefore, premarital relationships include sexual and romantic relationships. Infidelity was reported by the participants who did not have sex before marriage and those who had sex. The difference is that infidelity was more frequent in people who had sex before marriage. Failed past love was the most repetitive subset of the concept of past issues, and it leads to marital infidelity in two cases. In the first case, the relationship with the old love was termi- nated at the time of the decision to marry, and the relationship was resumed after a while.

Sina said:

"I had a lot of sex before I got married, and even my wife knew it, and we saw a counselor several times. She hoped I would give it up after marriage. She married me. I had no relationship for about a year, but I couldn't stand it and started it again."

Hamzeh said:

"From the beginning of my marriage, I was always thinking about my girlfriends. I was friend with a lot of girls, maybe 30 girls or more. I had sex with a girl I had been friends with for 8 years. I loved diversity since I was single, and I was friend with several girls at the same time."

Most of the participants stated that they had satellite dishes at home. More than half of them acknowledged the effect of movies shown by satellite channels on changing attitudes and starting and continuing an extramarital affair. Using characters in satellite channel movies and pornographic films as role models as well as watching some corrupt behaviors on the Internet and 
social media had led some individuals to engage in marital infidelity.

Masoud said:

“All people are engaging in such relationships. If you want to enjoy this short life, you have to be like everyone else and enjoy it. Don't you see on movies and TV shows that things are higgledy-piggledy and everyone is doing these affairs?"

\section{Sarah said:}

"Before I got married, I was very interested in satellite movies, especially those shown by Farsi 1 . If the characters in the movie cheated on their partners, I would put myself in their shoes and empathize with them. Early in my relationship with my brother-in-law, these movies helped me a lot to accept it."

The formation of the context for marital infidelity when meeting the spouse and getting ready for marriage

When a man is much older than his wife or vice versa, after a certain age, his sexual ability usually decreases, and he cannot meet the wife's sexual needs. This point was stated by some of the participants in this study.

Taqi said:

"My wife and I were always arguing. She used to blame me. We had a child one year after the wedding. She was much younger and handsome than me. She always told me that I was a bad-tempered nasty old man. But I tried to tolerate everything."

Since this woman was older than her husband, they had some differences in terms of ideologies and interests. In addition, the woman was unable to meet her husband's sexual needs. Furthermore, financially motivated marriage is an issue pointed out by some participants. For instance, in many couples referred to the family court for infidelity, the wife had a better economic position.

Fahimeh said:

"My husband was a shop assistant. He always acted in a way that I thought he loved me. After 12 years, I learned that he had bought a bachelor pad with my money and had sexual affairs with many women."

Women's employment and their strong sexual desire made some women look instrumentally at marriage. In most of these marriages, women were much older than their husbands, and from the beginning, there had been no love between them.

Fahimeh said:

"I was 35 years old, and my husband was 28 years old. This age disparity has led to many differences. For example, he used to drive very fast and swerve. He wore bizarre sunglasses, usually preferred by coxcomb young men. I couldn't satisfy him sexually. He was young anyway, and his age required him to do these things. I knew from the very beginning that he wanted me for my house and car."

One of the patterns of marriage pointed out by some participants was forced marriage. Mandatory social pressures such as girls' old age, fear of remaining single, male unemployment, and the disturbing context of the family forced some people to marry. In society in general and in small communities in particular, the girl's aging is stigmatized as a social anomaly. Many young girls have to marry to avoid being stigmatized as a spinster.

\section{Sahar said:}

"I was 18 years old, and I did not want to get married. I was forced to marry my cousin. I hated this marriage. My mother said that as all people in the family would talk about our marriage, we would be disgraced if I did not get married. I was not allowed to talk at all, and the whole family was determined to make this marriage happen. I resisted to the death, but it was of no use. I was just crying. They said I did not understand, and they intended to make me happy."

Usually, when a man loses his wife for some reason, especially when he has children, he runs into some problems. Besides, as remarriage is easier for men in Iranian society, people urge the man to remarry.

\section{Hamid said:}

"Ten years ago, my wife died, and I had two children. My family members and relatives insisted that I must get married. They introduced a girl who was 15 years younger than me. I didn't want to marry her. But they insisted that since there were some rumors about your marriage with her, you had to marry her." 


\section{The formation of the context for marital infidelity} during marital life

One of the most important factors influencing the participants' tendency to engage in marital infidelity was their low sexual satisfaction.

\section{Romina said:}

"My husband looked at me like a slave and only wanted me for sex, and he didn't kiss and caress me while he was having sex with me."

\section{Masoumeh said:}

'I'd like to have sex twice a week. We haven't had sex for three months. I have had little sex with my husband. Sometimes it is once every six months. It's been like this for about 10 years."

The satisfaction of emotional needs in the marital relationship is essential. In this study, most of the female participants and some male participants pointed to many problems in satisfying their sexual needs and considered it a reason for their infidelity. Although the lack of love and affection in the marital relationship is an important problem for both men and women, men like their love to be appreciated by their wives, and women are interested in receiving love from their husbands constantly and in different ways.

\section{Diana said:}

"My husband does not love me. After five years of living together, I have reached the end of the line. I'm a young woman, I want a lot of love, but my husband does not understand me. Now I'm looking for love, but I don't know where to find it. I regret why I married him. He is just caring for himself and stuffing his stomach with food. I reached the end of the line."

\section{Samira said:}

"Believe me that he does not understand what love means at all! A man marries a woman to love her, so what do you think I should do when he does not? I should either marry another man or have affairs with another man."

In the post-marital phase, economic growth can be a factor leading to infidelity in men. However, some female participants admitted that they committed marital infidelity only because of the economic and financial problems and their husband's unemployment that affected them and their families.
Shiva said:

"Eight years ago, my husband and I got married traditionally. We had a good life until he was very well off. At first, he was just dating women, but after a while, he told me that he had some concubines. As I loved him so much, I turned a blind eye to it. Because his factory had been transferred to a small town, I left university to be with him; maybe he would not do this again, but it was useless. I decided to divorce three years ago, but I found out I was pregnant. He promised not to do this, but he did not keep his promise. We saw a psychiatrist, and he said that my husband should take medicines. He behaved well for a while, but he stopped taking his medicines. I want to get out of his life".

Raha said:

"There were other reasons, too. I had affairs with another man because of the poverty and poor economic conditions. We had no money, and I saw my child was dying because of poverty and this miserable situation."

The husband's addiction, unemployment, and socializing with addicted friends were reasons pointed out by some of the participants accounting for their marital infidelity.

Sahar said:

"Two years after our marriage, I realized that in addition to unemployment, my husband used drugs and paid less attention to me. Sometimes he had sex with me under dress. I, who was young and saw how other people were living, wanted not to lag, so I started finding a boyfriend."

\section{Predictors of marital infidelity}

\section{Marital conflicts}

Marital conflicts were one of the reasons for marital infidelity.

Susan said:

"He always insulted me, humiliated me, and punished me emotionally. How much aggression! How much shouting! I never heard him talk to me kindly. He was always shouting at me."

Sahand said:

"Whenever there is a slight problem, my wife humiliates me very much and speaks very harshly and disrespectfully, as if I am her slave and she is the master. No 
matter who is listening to her, she keeps saying that I'm the most helpless and clumsy man she has ever seen. She says that I'm so incompetent that I cannot handle even the smallest matter in life."

Fahimeh said:

"This guy [her husband] did not socialize with anyone at all. He was at work all day. When he came home, he was either sleeping or having his nose in his cell phone. Then he suddenly started shouting. I wondered why all his life was work and playing with his cell phone. I had nothing to do but stare at walls and objects in the house and serve him. Alas, for a bit of attention and care for me! He was always tired or busy with work."

\section{Emotional apathy}

The present study results showed that emotional apathy in most cases was a reason for the participants' engagement in marital infidelity. The themes associated with this concept are shown in Table 1. The following are examples of participants' statements about emotional problems in their marital relationships.

\section{Diana said:}

"My husband does not love me. After five years of living together, I have reached the end of the line. I'm a young woman with many desires. I want a lot of attention and love, but my husband does not understand me. Now I am looking for love, but I do not know where to find it. I regret why I married him. He just cares about himself and stuffing his belly with food. I reached the end of the line."

"You have to be always alone. When your husband hurts your pride, you get tired. You need someone to talk to and understand you."

Most women who committed marital infidelity stated that they were often angry with their husbands and did not talk to each other because of misunderstandings and constant arguments and quarrels with their husbands.

\section{Mansoureh said:}

"We didn't talk and were at tantrums at home most of the time, sometimes lasting two or three months. Six months ago, I did not talk to him for a month. I slept in a separate room. But he did not apologize to me. I did not talk to him and only made food for him. This affected me a lot and made me want to have affairs with other men because I learned that I could not really get a divorce and that he could not really satisfy me spiritually. I wondered this helped me to forget the things he did. I am on bad terms with him for four months a year and live in my father's house. I am constantly going and coming."

The participants stated that they expected their spouses to pay attention to their feelings and emotions and to praise their appearance, clothing, and beauty, and to pay more attention in the presence of other people. They also stated that their expectations were met in most cases, and they have always faced unkindness and disregard by their spouses. This need was met mainly by sexual partners, which was one of the reasons for their tendency to have extramarital affairs.

\section{Mohsen said:}

"Despite my wife's disinterest and her rejection, I always did my best to attract her attention. I took her to travel, I bought many things for her ... but my wife did not pay any attention to me, and she did not care. This made me very upset, but when I think about it, I wonder if I did not do these things, what should I have done. But I did not betray my wife and did not divorce her."

Some participants stated that they hated their spouses from the beginning of their marriage due to forced marriages, and some even after marriage due to marital issues and problems.

\section{Sahar said:}

"The biggest mistake in my life was marrying my husband. I have regretted my marriage many times. I do not like to go to bed and sleep with her at all. We have been separated for months. I hate my life because I did not marry out of love. I do not love him at all. When he touches me, I want to shout. I go to bed early lest he asks to have sex. I'm just making excuses. I had to live with him because of the kids."

Some participants stated that not having time for a good emotional relationship with the wife, who expects the most love and expression of love from her husband, has caused the wife to fill this emotional gap by getting into relationships with bad friends. They filled this gap by bringing her into extramarital relations.

\section{Hamidreza said:}

"I was not home 24 days a month, and thus, my wife had to go to university to escape from loneliness and fill my absence." 


\section{Sexual apathy}

The study results indicated that sexual apathy was one of the reasons that made some participants engage in extramarital relationships.

One of the most common problems in women's sexuality was their husbands' premature ejaculation. They stated that despite having had this problem for several years, their husbands refused to seek treatment.

Samaneh said:

"We have sex once every two months, and it takes only about 2 minutes. It has been like this since the beginning of our marriage. He has premature ejaculation. He does not arouse me, and I am not sexually satisfied."

An analysis of the participants showed that men's unawareness of preparing their wives before having sexual intercourse caused sexual dissatisfaction and apathy in some women.

\section{Susan said:}

"Before having sex, he does not prepare me sexually. He just said, let's do it. I told him what about me. When he was satisfied, he left me. I beg him to touch and caress me, but he does not pay attention. I was never satisfied sexually in my life."

\section{Romina said:}

"My husband looked at me like a slave and only wanted me for sex, and he didn't kiss and caress me while he was having sex with me."

Most participants pointed to the spouse's frigidity and impotence and not seeking treatment as one of the reasons behind their sexual dissatisfaction.

\section{Masoumeh said:}

"I'd like to have sex twice a week. We haven't had sex for three months. I have had little sex with my husband. Sometimes it is once every six months. It's been like this for about 10 years."

\section{Hamzeh said:}

"She did not allow me to have sex with her. We had sex only once, on the first night of our marriage. She told me she hated these things and asked me I have to give her my house, so she let me have sex with her."

\section{Meisam said:}

"The thing that bothered me the most was my impotence. I couldn't have sex with my wife for about three years. Our relation was like that of a prisoner and warder. I had just to control her so that she did not have affairs with anyone. My wife always blamed me and asked me to have sex with her, and she started fighting and quarreling at home."

Some participants stated that their intense sexual desires and the inability of their spouses to meet their needs led to severe sexual dissatisfaction, anger, and irritability. The sexual desires were so intense that some masturbated, and in some cases, their spouses responded to their sexual needs with contempt.

\section{Ali said:}

"After a while, our sexual relationship got worse. She didn't allow me to be satisfied at all. I was very dissatisfied with this issue, and since then, she started making a fuss at home."

\section{Engaging in marital fidelity}

\section{Engaging in sexual relationships with a third per-} son

Monir said:

"I suddenly ended up having affairs with someone other than my husband. I asked myself what I was doing. I really do not know what happened. But it happened, and I felt I was interested in him.”

\section{Nahal said:}

"We had a problem with each other, and I hated him and needed someone to be with me to pull me out of this mire. It didn't matter to me that I loved him. I finally found a boyfriend. Things got a little better for me temporarily, but when I came home, I had to face the same terrible situation."

\section{Mohsen said:}

"I really did not want to end up in this relationship, but I do not know what happened that I developed an interest in her. I liked to talk to her, go out, and spend time with her." 
Mansoureh said:

"He humiliated me and blamed me so much that I could not stand him anymore. All this made me allow myself to make friends with someone else to escape this situation."

Ladan said:

"Little by little, I got emotionally interested in him. Being with him was like a new world for me."

Maryam said:

"Most of the time, I was on bad terms with my husband. He insulted and beat me. But I could not do anything. His offenses and beatings made me hate him. Finally, I met a shopkeeper, and I am still taking revenge on my husband."

\section{Engaging in parallel relationship}

Saba said:

"I was not really unfaithful, but I did not love him. There was no other choice because two months after the marriage, I realized that he was very bad-tempered and insulting. Still, my family members forced me to keep living with him because of nonsense prejudices and the belief that an engaged girl should not get a divorce as it will devalue her."

Raha said:

"I could neither get a divorce nor do anything else. I had to enter into a relationship with someone else without leaving my relationship with my husband."

"There were other reasons, too. I had affairs with another man because of the poverty and poor economic conditions. We had no money, and I saw my child was dying because of poverty and this miserable situation."

Sahar said:

"I was not the type of person to make friends with someone other than my husband. Everything went hand in hand to make this happen. I was 18 years old, and I did not want to get married. I was forced to marry my cousin. I hated this marriage. My mother said that as all people in the family talked about our marriage, we would be disgraced if I did not get married. I was not allowed to talk at all, and the whole family was determined to make this marriage happen. I resisted to the death, but it was of no use. I was just crying. They said I did not understand, and they intended to make me happy."

\section{Consequences of marital infidelity}

\section{Emotional divorce}

Susan said:

"Right now, we have no emotional connection ... and we got an emotional divorce so that when he wants to touch me, I have a disgusting feeling. But since I received nothing from him and I waived my marriage portion, I just want to find a change and get a divorce."

Soheila said:

"We were just living in the same house. We did not accept the problems or just kept silent."

Saeed said:

"I had no trust in her, and I was really helpless to solve all this misery."

Saba said:

"There was no verbal or emotional connection between us, and I preferred to run away from home."

\section{Nima said:}

“Our only problem was emotional divorce. I think I'm a flexible person that can get along with this situation. I told her that the only problem was that she did not listen to me and was stubborn. I told her we could not have a good life if she did not give up her arrogance. But she said that she was tired of this life, and neither I nor this life had any attraction for her. She said that she was tired of all these problems. To be honest, I could not get along with this situation. In fact, I was worn out and did not like our marital life."

Sahar said:

"I wanted to spend all my time with my child, and I didn't want to be with him at all."

Donya said:

"We didn't have any sexual, physical, or verbal relationships. I think we just lived together in the same house but had no feelings for each other." 


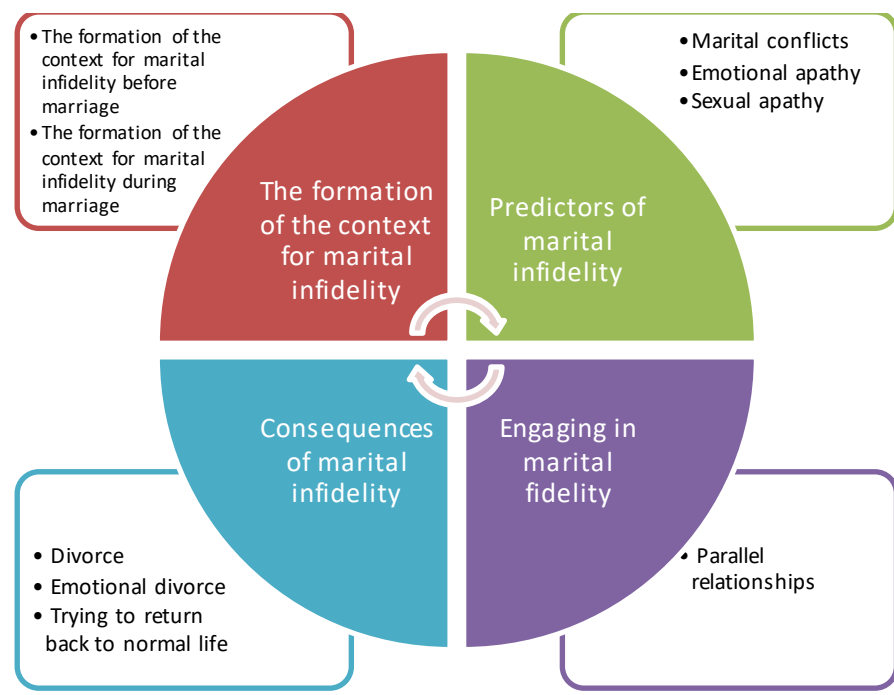

Figure 1. The process and contextual conditions of marital infidelity

Divorce

Samira said:

"There was no way but divorce, and we separated."

Morteza said:

"When I finally got a divorce, I felt that I was released forever from this dirty life that I was stuck in."

\section{Sahar said:}

"It was only a divorce that could get me out of this quagmire, and I didn't want to stand him for a moment after I learned he betrayed me."

Mina said:

"I tolerated this situation for the sake of my child, but he did not change. I found that the only way was separation."

Seeing a counselor and trying to get back to normal life

\section{Zahra said:}

"It was tough work to forgive him, but he regretted it. I did not want to ruin my life. We referred to a counselor and did everything to get our happiness back."
Mohadaseh said:

"Anyway, I made a mistake; I was really sorry; I was not such a person. It was the first time I made such a mistake. I wanted to compensate for it, and I did my best."

Babak said:

"When my wife realized about my affairs, she did not talk to me for a long time, but she forgave me because she knew I regretted it and I love her. We are doing our best to make our lives better."

\section{Back to normal life}

Zahra said:

"Thank God that this nightmare is over forever, now I feel really happy. I do not want to think about this even for a moment."

\section{Saeed said:}

"It's good we didn't get divorced. Anyway, everyone can make mistakes in life. We forgave each other for the sake of our life and gave a new life to our lives, and now we have no problem."

Hamid said:

"Although it was hard to return to normal life after all that happened, I proved to my wife that I love her and that it was just a childish mistake, and my wife is really good." 
Mohsen said:

"It's been about two and a half years now since that event. I don't like to talk about it. But I'm happy that it's over and we're back to our normal life. I don't allow our life and happiness to be endangered."

As seen in Figure 1, marital infidelity from formation, engagement, and adjustment generally takes place in four stages: the formation of the context of marital infidelity, predictions of marital infidelity, engaging in marital infidelity, and the consequences of marital infidelity.

\section{Discussion}

The present study explored the process and contextual conditions of marital infidelity. The analysis of the participants' interviews indicated that marital infidelity from formation, engagement, and adjustment generally takes place in four stages: the formation of the context of marital infidelity, predictions of marital infidelity, engaging in marital infidelity, and the consequences of marital infidelity. Previous studies have shown several factors accounting for the formation of infidelity in marital relationships. For example, Satples, (2012) and Jackman (2015) reported that the personality traits such as extroversion and narcissism could serve as factors underlying marital infidelity. Besides, lack of internal adherence to religious beliefs can be a factor accounting for people's tendency to engage in marital infidelity (KhodabakhshiKoolaee et al., 2017).

Adherence to religious beliefs, mutual respect, and couples' knowledge of each other can increase the durability and stability of their marriage (Jamalnik, Falsafinejad, Khodabakhshi-koolaee, 2020). Turliuc and Scutaru (2013) showed that the absence of dynamic relationships, sexual dissatisfaction, and lack of attractiveness could be other underlying factors of infidelity in marital relationships. Abbasi, Gholamzadeh Jofreh \& Morgan (2020) reported six main themes related to marital infidelity among Iranian women: partners' emotional issues, cultural and social factors, substance abuse, partners' psychological issues, financial worries, and sexual concerns (Abbasi et al., 2020). Spousal violence and communication problems are other factors associated with infidelity among men and women. For example, Majumdar (2018) showed that young women resort to online infidelity to avoid conflicts and spousal violence (Majumdar, 2018).

The poor economic situation and financial problems faced by couples were other causes of infidelity in marital life. For example, Wanjiru et al. showed a negative rela- tionship between a spouse's monthly income and infidelity. The lower the family income, the greater the involvement of the spouse in infidelity (Wanjiru, Ireri, \& Menecha, 2020). Family-of-origin experiences, parental infidelity, family conflicts, and individuals' infidelity beliefs.

Overall, the present study showed that marital infidelity begins in the premarital stages. This outcome is due to the individuals' personality traits and religious beliefs. Then it continues with choosing and getting to know the spouse, followed by the risk factors after marriage and during marital life, all leading to marital infidelity. The contextual conditions for marital infidelity are developed due to marital conflicts, emotional apathy, sexual dissatisfaction, economic problems in the family, and physical and verbal violence experienced by spouses. Marital infidelity is formed by engaging in relationships with a third person and starting parallel relationships.

The consequences of marital infidelity include emotional divorce, divorce or seeing a counselor, and trying to return to a normal life. However, these steps are not completely independent of each other, and there are reciprocal relationships between them. For instance, getting into relationships with a third person increases the emotional and sexual apathy between couples, which can have consequences such as emotional divorce, divorce, or referring to a counselor. These findings reveal the need for paying more attention to the issue of marital infidelity and identifying the process and contextual factors accounting for marital infidelity. Accordingly, it is essential to develop and implement effective programs to prevent and reduce the incidence of marital infidelity. Besides, future studies can explore risk factors for marital infidelity in larger samples.

\section{Conclusion}

The present study showed that marital infidelity is a complex and multidimensional phenomenon, and people tend to engage in marital infidelity for various reasons. Therefore, this phenomenon must be dealt with by considering these complexities, and a single solution cannot be offered to everyone. The four main stages of marital infidelity of formation of the context of marital infidelity, predictions of marital infidelity, engaging in marital infidelity, and the consequences of marital infidelity are interrelated. 


\section{Ethical Considerations}

\section{Compliance with ethical guidelines}

This research was registered at Islamic Azad University, Tehran Research and Science Branch (Code: IR.IAU. SRB.REC.1398.229.

\section{Funding}

This article reports the results of a doctoral dissertation by the first author in counseling at the Islamic Azad University, Science and Research Branch.

\section{Authors' contributions}

All authors equally contributed to preparing this article.

\section{Conflict of interest}

The authors declared no conflict of interest.

\section{Acknowledgments}

The authors would like to thank the participants and the officials of the courts of law and marriage and family therapy clinics in Tehran who helped the authors in conducting this study.

\section{References}

Abbasi, A., Gholamzadeh Jofreh, M., \& Morgan, M. M. (2020) Grounds for infidelity among Iranian women: A phenomenological study. The American Journal of Family Therapy, 49(3), 251-65. [DOI:10.1080/01926187.2020.1813652]

Apostolou, M. (2019). Why Greek-Cypriots cheat? The evolutionary origins of the big-five of infidelity. Evolutionary Behavioral Sciences, 13(1), 71-83. [DOI:10.1037/ebs0000140]

Baucom, D. H., Pentel, K. Z., Gordon, K. C., \& Snyder, D. K. (2017) An integrative Approach to Treating Infidelity in Couples. In J. Fitzgerald (Ed.), Foundations for Couples' Therapy (pp. 206-15). New York: Routledge. [DOI:10.4324/9781315678610-21]

Brown, E. M. (2013). Patterns of infidelity and their treatment. New York: Routledge. [DOI:10.4324/9780203782743]

Creswell, J. W., \& Báez, J. C. (2020). 30 Essential skills for the qualitative researcher. California: Sage Publications. https://books. google.com/books?id=kvXbDwAAQBAJ\&dq
Ein-Dor, T., Perry-Paldi, A., Hirschberger, G., Birnbaum, E. G. \& Deutsch, D. (2015). Evolution and human behavior. Evolution and Human Behavior, 36(1), 17-24. [DOI:10.1016/j.evolhumbehav.2014.08.002]

Farooq, Z., \& Fatima, I. (2018). Predictors of relational turbulence in early years of marriage. Journal of Behavioural Sciences, 28(1), 70-87. https://www.researchgate.net/ publication/327932351_Predictors_of_relational_turbulance_ in_early_years_of_marriage

Fife, S. T., Weeks, G. R., \& Stellberg-Filbert, J. (2013). Facilitating forgiveness in the treatment of infidelity: An interpersonal model. Journal of Family Therapy, 35(4), 343-67. [DOI:10.1111/ j.1467-6427.2011.00561.x

Fincham, F. D., \& May, R. W. (2017). Infidelity in romantic relationships. Current Opinion in Psychology, 13, 70-4 [DOI:10.1016/j.copsyc.2016.03.008] [PMID]

Foster, J. D., \& Misra, T. A. (2013). It did not mean anything (about me) cognitive dissonance theory and the cognitive and affective consequences of romantic infidelity. Journal of Social and Personal Relationships, 30(7), 835-57. [DOI:10.1177/0265407512472324]

Gordon, K. C., Baucom, D. H., \& Snyder, D. K. (2005). Treating couples recovering from infidelity: An integrative approach Journal of Clinical Psychology, 61(11), 1393-405. [DOI:10.1002/ jclp.20189] [PMID]

Hawkins, A. J., Willoughby, B. J., Doherty, W. J. (2012). Reasons for divorce and openness to marital reconciliation. Journal of Divorce \& Remarriage, 53(6), 453-63. [DOI:10.1080/10502556.2 012.682898

Jackman, M. (2015). Understanding the cheating heart: What determines infidelity intentions? Sexuality \& Culture, 19(1), 7284. [DOI:10.1007/s12119-014-9248-z]

Jahan, Y., Chowdhury, A. S., Rahman, S. A., Chowdhury, S., Khair, Z., \& Huq, K. E., et al. (2017). Factors involving extramarital affairs among married adults in Bangladesh. International Journal of Community Medicine and Public Health, 4(5), 1379-86. [DOI:10.18203/2394-6040.ijcmph20171506]

Jamalnik M, Falsafinejad M R, Khodabakhshi-koolaee A. (2020) Long-term marital satisfaction: Couples' narratives of the role of mate selection. Journal of Client-centered Nursing Care, 6(4), 301-10. [DOI:10.32598/JCCNC.6.4.337.1]

Jenkins, T. Q. (2015). Husband's response infidelity $[\mathrm{PhD}$ dissertation]. Kentucky: University of Kentucky. https://uknowledge.uky.edu/cgi/viewcontent. cgi?article $=1028 \&$ context $=$ hes_etds

Jones, D. N., \& Weiser, D. A. (2014). Differential infidelity patterns among the Dark Triad. Journal of Personality and Individual Differences, 57(1), 20-4. [DOI:10.1016/j.paid.2013.09.007]

Khodabakhshikoolaee, A., Bahrami, S., \& Rasstak, H. (2017) [The quality of love and sexual satisfaction survey among loyal and unfaithful married men (Persian)]. Quarterly Journal of Social Work, 5(4), 12-5. http:// socialworkmag.ir/article1-177-en.html

Koolaee, A., Motlagh, T., Esmaili, A., \& Rahmatizadeh, M (2014). [The comparison of early maladaptive schema and intimacy in marital infidelity and non-infidelity men (Persian)] Iranian Journal of Psychiatric Nursing, 2(3), 12-23. http://ijpn. ir/article-1-395-en.html 
Guba, E. G., \& Lincoln, Y. S. (1994). Competing Paradigms in Qualitative Research. In N. K. Denzin, \& Y. S. Linkoln (Eds.), Handbook of Qualitative Research (pp. 105-17). Thousand Oaks, CA: Sage. https://eclass.uoa.gr/modules/document/file. php/PPP356/Guba\%20\%26\%20Lincoln\%201994.pdf

Majumdar, S. (2018). Online Infidelity and Intimate Partner Violence: Exploring Their Perceived Association Among Young Adults in India. In S. P. Sahni, \& G. Jain (Eds.), Internet Infidelity (pp. 133-45). Singapore: Springer. [DOI:10.1007/978981-10-5412-9_8]

Mark, K. P., Janssen, E., \& Milhausen, R. R. (2011). Infidelity in heterosexual couples: Demographic, interpersonal, and personality-related predictors of extradyadic sex. Archives of Sexual Behavior, 40(5), 971-82. [DOI:10.1007/s10508-0119771-z] [PMID]

Munsch, C. L. (2018). Her support, his support: Money, masculinity, and marital infidelity. American Sociological Review, 80(3), 469-95. [DOI:10.1177/0003122415579989]

Olson, D., DeFrain, J., \& Skogrand, L. (2010). Marriages and families: Intimacy, diversity, and strengths. New York: McGraw-Hill Education. https://books.google.com/ books?id=1EW6QwAACAAJ\&dq

Özgün, S. (2010). The predictors of the traumatic effect of extramarital infidelity on married women: coping strategies, resources, and forgiveness in partial fulfillment of the requirements for the degree of doctor of philosophy in the department of psychology [PhD dissertation]. Ankara: Middle East Technical University. https://www.researchgate.net/ publication/331482749_

Satples, J. M. (2012). Couples' process of healing from infidelity while in therapy [PhD dissertation]. Las Vegas: University of Nevada. [DOI:10.34917/4332760]

Shackelford, T. K., Besser, A., \& Goetz, A. T. (2008). Personality, marital satisfaction, and the probability of marital infidelity. Individual Differences Research, 6(1), 13-25. https://www.toddkshackelford.com/downloads/Shackelford-Besser-GoetzIDR-2008.pdf

Snyder, D. K., Baucom, D. K, \& Gordon, K. C. (2007). Treating infidelity: An Integrative Approach to Resolving Trauma and Promoting Forgiveness. In P. R. Peluso (Ed.) Infidelity: A Practitioner's Guide to Working With Couples in Crisis. New York: Routledge. https://books.google.com/ books?id=57OTAgAAQBAJ\&dq

Tsapelas, I., Fisher, H. E., \& Aron, A. (2010). Infidelity: When, Where, Why. In W. R. Cupach, \& B. H. Spitzberg (Eds.), The Dark Side of Close Relationships II (pp. 17596). New York: Routledge. https://books.google.com/ books?id=HdOLAgAAQBAJ\&dq

Turliuc, M. N., \& Scutaru, E. L. (2013). A semi-model of predictive factors for mixed infidelity. Annals of AII Cuza University. Psychology Series, 22(2), 35-51. https://www.researchgate net/publication/272177848_A_Semi-model_of_Predictive_ Factors_for_Mixed_Infidelity

Wanjiru, V., Ireri, N., \& Menecha, J. B. (2020). An investigation of the factors contributing to infidelity among married couples in selected mainstream churches in kikuyu constituency, Kiambu County, Kenya. Journal of Sociology, Psychology E Religious Studies, 2(2), 1-8. https://stratfordjournals.org/journals/index.php/Journal-of-Sociology-Psychology/article/view/629
Wright, R. (1994). The moral animal: The new science of evolutionary psychology. New York: Pantheon Books. https://books. google.com/books?id=r5SBAAAAMAAJ\&q 